CLINICAL STUDY

\title{
Vitamin D deficiency in postmenopausal, healthy women predicts increased cardiovascular events: a 16-year follow-up study
}

\author{
Louise Lind Schierbeck, Lars Rejnmark ${ }^{1,6}$, Charlotte Landbo Tofteng, Lis Stilgren ${ }^{2}$, Pia Eiken ${ }^{3}$, Leif Mosekilde ${ }^{1,6}$, \\ Lars Køber ${ }^{4,5}$ and Jens-Erik Beck Jensen \\ Department of Endocrinology, Hvidovre Hospital, afd. 541, Kettegård alle 30, 2650 Hvidovre, Denmark, ${ }^{1}$ Department of Medicine and Endocrinology, \\ MEA, Aarhus University Hospital, Tage Hansens gade 2, 8000 Aarhus C, Denmark, ${ }^{2}$ Department of Endocrinology, Svendborg Hospital, Valdemarsgade \\ 53, 5700 Svendborg, Denmark, ${ }^{3}$ Department of Cardiology, Nephrology and Endocrinology, Hillerod Hospital, Dyrehavevej 29, 3400 Hillerod, Denmark, \\ ${ }^{4}$ Department of Cardiology, Rigshospitalet, Blegdamsvej 9, 2100 Copenhagen Ø, Denmark, ${ }^{5}$ Faculty of Health and Medical Sciences, University of \\ Copenhagen, Blegdamsvej 3B, Copenhagen, Denmark and ${ }^{6}$ Faculty of Health, University of Aarhus, Nordre Ringgade 1, 8000 Aarhus C, Denmark \\ (Correspondence should be addressed to L L Schierbeck; Email: louise.schierbeck@gmail.com)
}

\begin{abstract}
Objective: To investigate the relationship between vitamin D status in healthy women and cardiovascular outcome.

Design and methods: Between 1990 and 1993, 2016 healthy, recently postmenopausal women were enrolled in the Danish Osteoporosis Prevention Study. Serum levels of 25-hydroxyvitamin D (25(OH)D, $\mathrm{nmol} / \mathrm{l}$ ) were measured at baseline. Participants were followed for 16 years. The primary end point was a combination of death, heart failure, myocardial infarction (MI) and stroke. Vitamin D deficiency was defined as serum $25(\mathrm{OH}) \mathrm{D}<50 \mathrm{nmol} / \mathrm{l}$. The primary end point was adjusted for other risk factors of adverse cardiovascular events (age, smoking, blood pressure, hip-waist ratio, education and family history of MI). Results: At baseline, mean age was 50 years and BMI 25. Women with vitamin D deficiency $(n=788)$ had more cardiovascular risk factors than vitamin D-replete women $(n=1225)$. Compared with vitamin D-replete women, women with low 25(OH)D levels had significantly higher BMI and triglycerides, lower HDL and hip-waist ratio and less education. More were smokers among the vitamin D deficient (47 vs $38 \%$ ). A primary end point was experienced by 118 (15\%) with vitamin D deficiency and by $125(10 \%)$ of the vitamin D replete. Hazard ratio (HR) was 1.49 (95\% confidence interval: $1.16-1.92 ; P=0.002)$ in the vitamin D deficient. Adjusted HR was $1.32(1.02-1.71 ; P=0.03)$. In total, 135 women died; of these, $65(8 \%)$ were of the vitamin D deficient and $70(6 \%)$ in the vitamin D-replete group; unadjusted HR was $1.44(1.02-2.01 ; P=0.04)$ for vitamin $\mathrm{D}$ deficiency.

Conclusion: Healthy women with vitamin D deficiency have increased risk of adverse cardiovascular outcome.
\end{abstract}

European Journal of Endocrinology 167 553-560

\section{Introduction}

Recently, a large observational study found vitamin D deficiency to be associated with an increased risk of coronary artery disease, diabetes, cardiomyopathy, hypertension and all-cause death (1). The theory of a relationship between vitamin $\mathrm{D}$ and cardiovascular disease (CVD) and mortality is not new $(2,3,4,5$, $6,7,8)$. The main dispute remains whether vitamin $D$ is just a marker for a worse prognosis $(9,10)$ potentially explained by other factors, as vitamin D deficiency has also been associated with obesity $(1,2,11)$, smoking (2), ageing $(1,12,13)$ and less physical activity $(2,11)$. Though the major source of vitamin D is dermal production triggered by the sun $(3,14)$, vitamin $D$ is also ingested and could thus be a marker of general diet composition. In this study, we have had the opportunity to adjust for various lifestyle factors including degree of education, leisure time physical activity and importantly diet. CVD may have a different pattern in men and women, and studying men and women separately eliminates some of the variation.

The aim was to investigate whether baseline vitamin D status in healthy postmenopausal women predicted cardiovascular outcome or mortality, when adjusting for important confounders that are common risk factors for vitamin D deficiency and CVD.

\section{Materials and methods}

\section{Study subjects}

The Danish Osteoporosis Prevention Study (DOPS) is a prospective multicentre trial evaluating the effect of postmenopausal hormone therapy (HT) as primary 
prevention of osteoporotic fractures. Women included in the study fulfilled the following criteria: healthy, recent postmenopausal Caucasian women aged 45-58 years, with last menstrual bleeding 3-24 months before study entry or perimenopausal symptoms (including irregular menstruations) in combination with postmenopausal serum FSH (FSH more than 2s.D. above the premenopausal mean). Hysterectomised women were included if aged 45-52 years, provided they had elevated postmenopausal serum FSH. Exclusion criteria were history of bone disease (including non-traumatic vertebral fractures on X-ray), uncontrolled chronic disease, previous or current cancer or thromboembolic disease, current or past treatment with glucocorticoids $>6$ months, current or previous HT use within the past 3 months or alcohol or drug addiction. Between 1990 and 1993, 2016 women were enrolled in a prospectively followed cohort, and of these, 1006 were randomly allocated to receive either HT or no treatment ( 502 on HT); the remaining 1010 women had personal choice (221 opted for HT). Two thousand and thirteen had baseline measurements of 25-hydroxyvitamin D $(25(\mathrm{OH}) \mathrm{D})$. Recruitment has previously been described in detail (14). Subjects gave informed consent before the study, which was conducted according to Helsinki II. The study was approved by the Central and Regional Ethics Committee (\# 1990/1821) and monitored by the Good Clinical Practice (GCP) unit at University of Aarhus, Denmark (ClinicalTrials.gov NCT00252408).

\section{Biochemistry}

Blood samples were collected at baseline after overnight fasting and serum was stored at $-80^{\circ} \mathrm{C}$ for later analysis. Serum levels of $25(\mathrm{OH}) \mathrm{D}(\mathrm{nmol} / \mathrm{l})$ were measured by RIA, preceded by specific extraction procedures with ether, preliminary chromatography and a competitive binding assay, using rat kidney-derived receptor binding protein (15). This method includes both vitamin D2 and D3 metabolites. The limit of detection was $12.5 \mathrm{nmol} / \mathrm{l}$; intra- and interassay coefficients of variation were 8.3 and $10.2 \%$ respectively.

Serum levels of intact parathyroid hormone (PTH) were measured at inclusion in 1095 subjects by DPC Immulite (chemiluminescense) with an interassay coefficient of variation of $11 \%$ and an intra-assay coefficient of variation of $6 \%$. Due to the smaller fraction of women with baseline measurements of PTH, it is not included in the final model. Baseline level of triglycerides was measured in 1437 women (71\%) and thus is also not included in the final model.

\section{Diet records}

The participants recorded daily intakes of food and beverages after being given oral and written instructions at baseline using 4- or 7-day diet records. Intakes did not differ between 4- and 7-day food records (16).
A trained dietician used food models and photographs during a 15-min individual validation interview to evaluate serving sizes and cooking habits. The diet content of calcium and vitamin D was analysed using a computerised database ('Dankost', software version $1.3 \mathrm{~b})$, containing information on diet composition based on official Danish food tables. The variation coefficient for intake of calcium from one measurement to the next was $15 \%$, and for vitamin D intake, it was $28 \%$. For the calculation of daily intakes, we added supplements of calcium and vitamin D. Moreover, smoking and alcohol consumption was registered at inclusion.

\section{Clinical measurements}

At baseline, BMI $\left(\mathrm{kg} / \mathrm{m}^{2}\right)$ was calculated from height and weight. Subjects were interviewed regarding lifestyle habits, including physical activity and gynaecological history. Family history of myocardial infarction (MI) was noted.

\section{Assessment of mortality and hospitalisation due to CVD}

The primary end point for this study was a combination of death, hospitalisation due to MI, heart failure (HF) or stroke. Secondary end points were the individual components of the primary end point.

On June 16, 2008, we ended our follow-up period by retrieving data on all studied subjects from the Danish Civil Registration System and the National Hospital Discharge Register. In the Danish Civil Registration System, we identified all women who had died or emigrated during follow-up, as this register has electronic records on all changes in vital status, including change of address and date of death or emigration for the entire Danish population since 1968 .

We identified women who had been hospitalised due to a CVD using the Danish National Hospital Discharge Register, which covers all contacts to the hospitals. The register was founded in 1977 and includes information on discharge diagnoses and date of discharge assigned exclusively by the physician at discharge according to the Danish version of ICD-8 until the end of 1993 and to the Danish version of the ICD-10 from 1994. The register has nationwide coverage of hospitals with an almost $100 \%$ completeness of recordings and a high precision of diagnoses (17). Using this register, we identified all study participants who had been assigned a diagnosis of CVD - classified as MI (ICD-10 code I21), HF (ICD-10 code I42+I50) and stroke (ICD-10 code I60-69). For the combined end point, the date of first incident was used.

\section{Statistical analysis}

Unless otherwise stated, all data are expressed as mean and s.D. Vitamin D deficiency is defined as $25(\mathrm{OH}) \mathrm{D}$ 
levels $<50 \mathrm{nmol} / \mathrm{l}$; if used as a continuous variable, levels of $25(\mathrm{OH}) \mathrm{D}$ was $\log$ transformed. The first incident diagnosed was used, and some women experienced more than one event; therefore, the number of composite end points appears lower than the addition of each component. All tests were two sided, and a $P$ value $<0.05$ was considered statistically significant. Dichotomous variables were tested with a $\chi^{2}$ test and continuous variables were tested with Student's $t$-test. Survival data and composite end point are presented using the Kaplan-Meier method and univariate and multivariable adjustments were performed using Cox proportional hazards regression analyses calculating hazard ratio (HR) with 95\% confidence intervals (CI). Model assumption including linearity of continuous variables and the proportional hazards assumption were tested and found to be valid unless otherwise indicated. In the multivariable analysis and in the Cox regression analysis, stepwise elimination (if $P>0.10)$ of insignificant variables was made. Statistical analyses were made with SAS version 9.2 (SAS Institute Inc., Cary, NC, USA).

\section{Results}

Baseline characteristics of vitamin D-deficient and vitamin D-replete women are given in Table 1 . Mean age was 50 years, and 788 (39\%) women had vitamin D deficiency.

Compared with vitamin D-replete women, women with vitamin D deficiency had lower hip-waist ratio and HDL and higher BMI, triglycerides, PTH and a trend towards higher fasting blood glucose. The vitamin D-deficient women were less physically active and less educated, more had a family history of MI and more were smokers. In addition, total daily energy intake as well as dietary intake of protein, calcium and vitamin $\mathrm{D}$ differed between groups with higher intakes in the vitamin D-replete compared with the vitamin D-deficient women (Table 1). Only 11 women took calcium supplements, while 55\% took over-the-counter vitamin tablets - mainly multivitamins - containing $5 \mu \mathrm{g}$ vitamin D. Dietary intake of vitamin D was primarily from meat, fish and eggs. Age was not correlated with $25(\mathrm{OH}) \mathrm{D}$ in this population. Levels of $25(\mathrm{OH}) \mathrm{D}$ was associated with intake of several nutrients, but none of the nutrients had any influence on the primary outcome. PTH correlated with 25-OHD and the Pearson correlation coefficient was -0.164 , $P<0.001$.

\section{Clinical outcome}

One hundred and twenty-five (10\%) vitamin D-replete women and $118(15 \%)$ vitamin D-deficient women experienced a primary end point. Overall CVD rates were low; 135 women died and few were hospitalised
Table 1 Baseline characteristics stratified on vitamin D status. Continuous variables are given as mean and S.D. in parenthesis.

\begin{tabular}{|c|c|c|c|}
\hline & $\begin{array}{c}\text { 25(OH)D } \\
<50 \mathrm{nmol} / \mathrm{l} \\
(n=788)\end{array}$ & $\begin{array}{l}\text { 25(OH)D } \\
\geq 50 \mathrm{nmol} / \mathrm{l} \\
(n=1225)\end{array}$ & $\begin{array}{c}\boldsymbol{P} \text { value } \\
\text { (t-test) }\end{array}$ \\
\hline Age (years) & $50.0(2.8)$ & $50.2(2.9)$ & 0.40 \\
\hline BMI $\left(\mathrm{kg} / \mathrm{m}^{2}\right)$ & $25.6(4.7)$ & $24.8(4.0)$ & $<0.001$ \\
\hline Hip/waist ratio & $1.27(0.13)$ & $1.28(0.12)$ & 0.04 \\
\hline $\begin{array}{l}\text { Systolic blood } \\
\text { pressure }(\mathrm{mmHg})\end{array}$ & $132(21)$ & $131(19)$ & 0.21 \\
\hline $\begin{array}{l}\text { Diastolic blood } \\
\text { pressure }(\mathrm{mmHg})\end{array}$ & $83(11)$ & $82(11)$ & 0.075 \\
\hline $\begin{array}{l}\text { Triglycerides } \\
(\mathrm{mmol} / \mathrm{l})^{*}\end{array}$ & $1.22(0.03)$ & $1.13(0.02)$ & 0.01 \\
\hline $\mathrm{HDL}(\mathrm{mmol} / \mathrm{l})^{*}$ & $1.69(0.43)$ & $1.76(0.45)$ & 0.002 \\
\hline LDL $\left(\mathrm{mmol} / \mathrm{l}^{*}\right.$ & $3.91(1.04)$ & $3.86(0.98)$ & 0.39 \\
\hline $\begin{array}{l}\text { Fasting glucose } \\
(\mathrm{mmol} / \mathrm{l})\end{array}$ & $4.70(0.71)$ & $4.64(0.68)$ & 0.055 \\
\hline $\begin{array}{l}\text { Total calcium } \\
(\mathrm{mmol} / \mathrm{l})^{*}\end{array}$ & $2.34(0.14)$ & $2.34(0.09)$ & 0.82 \\
\hline $25(\mathrm{OH}) \mathrm{D}(\mathrm{nmol} / \mathrm{l})$ & $35(10)$ & $80(26)$ & $<0.001$ \\
\hline $\mathrm{PTH}(\mathrm{pmol} /)^{*}$ & $4.3(2.4)$ & $3.9(1.9)$ & 0.006 \\
\hline Exercise (h/week) & $5.51(5.11)$ & $6.28(4.84)$ & $<0.001$ \\
\hline $\begin{array}{l}\text { Postmenopausal } \\
\text { hormone treatment }\end{array}$ & $279(35 \%)$ & $441(36 \%)$ & 0.79 \\
\hline Smoking (yes) & 369 (47\%) & $462(36 \%)$ & $<0.001$ \\
\hline Family history of MI & $66(9 \%)$ & $64(5 \%)$ & 0.005 \\
\hline $\begin{array}{l}\text { Number of cheroots/ } \\
\text { cigarettes }\end{array}$ & $7.1(9.0)$ & $5.4(8.3)$ & $<0.001$ \\
\hline \multicolumn{4}{|l|}{ Daily intake } \\
\hline Energy (kJ) & 7553 (1824) & 7779 (1855) & 0.009 \\
\hline Protein (g) & $65(15)$ & 67 (17) & 0.005 \\
\hline Fat $(\mathrm{q})$ & 77 (24) & $78(24)$ & 0.33 \\
\hline Sodium (mg) & 2137 (631) & $2146(614)$ & 0.77 \\
\hline Calcium (mg) & 837 (327) & 874 (344) & 0.021 \\
\hline Vitamin D ( $\mu \mathrm{q})$ & $2.72(2.41)$ & 3.28 (3.31) & $<0.001$ \\
\hline
\end{tabular}

All variables with more than $5 \%$ missing data are denoted with an asterisk.

due to a MI $(n=35)$, HF $(n=18)$ or stroke $(n=89)$ during the 16 years of follow-up.

Primary end point The composite end point (mortality, MI, HF or stroke) was experienced by 243 women: 118 (15.0\%) with vitamin D deficiency and 125 (10.2\%) who were vitamin D replete. Accordingly, as shown in Table 2 and Fig. 1, vitamin D deficiency was associated with an increased risk of the primary end point (HR: 1.49, CI: $1.16-1.92, P=0.002)$.

Adjustment for age, family history of MI, tobacco use, systolic blood pressure, level of education and hip-waist ratio did not change risk estimates to any major degree (HR: 1.32; CI: 1.02-1.71, P=0.034; Table 2). Adding PTH to the final model did not change the risk estimate of vitamin D deficiency (HR: 1.30, CI: 0.92-1.85).

Levels of triglycerides at baseline were also associated with an increased risk of the primary end point; however, if triglycerides were added to the model, it did not change the risk estimate for vitamin D deficiency. Leisure time physical activity was significantly associated with $25(\mathrm{OH}) \mathrm{D}(P<0.0001)$ but did not correlate with any of the outcome measures and hence was not included in the final model. 
Table 2 Components of the primary end point and the composite end point stratified by 25(OH)D at baseline with univariate and adjusted (multivariable) hazard ratios (HR) of events in vitamin D-deficient $(n=788)$ vs vitamin D-replete $(n=1225)$ participants.

\begin{tabular}{|c|c|c|c|c|c|c|}
\hline & \multicolumn{2}{|c|}{ Events (\%) } & \multicolumn{2}{|c|}{ HR $(95 \% \mathrm{Cl})$} & \multicolumn{2}{|c|}{ HR $(95 \% \mathrm{Cl})$} \\
\hline & Vitamin D deficient & Vitamin D replete & Univariate & $P$ value & Multivariable $^{a}$ & $P$ value \\
\hline Mortality & $65(8.3)$ & $70(5.7)$ & $1.44(1.02-2.01)$ & 0.036 & $1.18(0.84-1.67)$ & 0.341 \\
\hline Heart failure & $10(1.3)$ & $8(0.7)$ & $1.97(0.78-4.99)$ & 0.153 & $1.88(0.71-5.01)$ & 0.206 \\
\hline Myocardial infarction & $13(1.7)$ & $22(1.8)$ & $0.93(0.47-1.84)$ & 0.824 & $0.83(0.41-1.67)$ & 0.596 \\
\hline Stroke & $47(6.0)$ & $42(3.4)$ & $1.76(1.16-2.67)$ & 0.008 & $1.68(1.10-2.56)$ & 0.017 \\
\hline Composite end point & $118(15.0)$ & 125 (10.2) & $1.49(1.16-1.92)$ & 0.002 & $1.32(1.02-1.71)$ & 0.034 \\
\hline
\end{tabular}

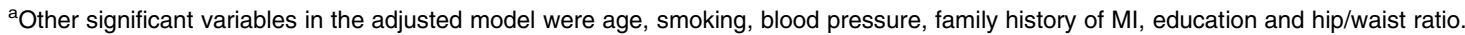

Smoking was in univariate analysis associated with a HR of 2.26 (CI: 1.75-2.93, $P<0.0001$ ) and each cigarette or cheroot/day was associated with a HR of 1.043 (CI: $1.031-1.056, P<0.0001$ ) for the primary end point. Smoking (as a dichotome variable) as well as number of cigarettes/cheroots per day correlated inversely to $25(\mathrm{OH}) \mathrm{D}(P<0.001)$. Table 3 shows the HRs associated with vitamin D deficiency for the primary end point, stratified by smoking status. For other predictors of the primary end point included in the final model, please see Table 4.

Secondary end points In univariate analysis, vitamin D deficiency was associated with an increased risk of death; $70(5.7 \%)$ vitamin D-replete women and $65(8.3 \%)$ vitamin D-deficient women died (HR: 1.44 , CI: 1.02-2.01, $P=0.04$; Fig. 2), but after adjustment, risk was no longer significantly increased (HR: 1.18, CI: $0.84-1.67, P=0.34)$. HF was diagnosed in 18 participants, ten $(0.7 \%)$ vitamin $\mathrm{D}$ replete and eight (1.3\%) vitamin D deficient (HR: 1.97, CI: 0.78-4.99, $P=0.15)$, MI in 35 participants $(22(1.8 \%)$ and 13 (1.7\%) respectively), HR: 0.93 (CI: $0.47-1.84, P=0.82)$ and stroke in 89 women $(42(3.4 \%)$ vitamin D replete and $47(6.0 \%)$ with vitamin D deficiency), HR: 1.76 (CI: $1.16-2.67, P=0.0075)$. There was no interaction between vitamin D deficiency and any of the other variables in the model.

Table 2 shows the number of events and the risk of the individual component of the primary end point. In crude as well as adjusted analysis, risk of stroke was significantly increased in the vitamin D-deficient women, whereas vitamin D deficiency was not associated with increased risk of hospitalisation due to HF or MI.

\section{Discussion}

In this population of 2013 healthy postmenopausal women, we found baseline $25(\mathrm{OH}) \mathrm{D}$ to be a predictor of later mortality or cardiovascular events. Even though sufficient $25(\mathrm{OH}) \mathrm{D}$ levels are associated with a healthier lifestyle, adjusting for important parameters such as smoking, blood pressure, age, family history of MI and hip-waist ratio did not obliterate the association. Importantly, we had information about physical activity and diet, but these were not - as often suggested - significant confounders in relation to $25(\mathrm{OH}) \mathrm{D}$ and outcome.

As $25(\mathrm{OH}) \mathrm{D}$ levels are inversely correlated with increasing tobacco use (2), it could be speculated that $25(\mathrm{OH}) \mathrm{D}$ levels in regard to cardiovascular outcome is a marker of smoking habits. However, by dividing the population into smokers and non-smokers, we found that vitamin D deficiency was associated with a higher HR (not statistically significant) for the primary end point in non-smokers than in smokers, and thus no indication of the suggested interpretation.

It is not surprising that vitamin $\mathrm{D}$ deficiency is associated with mortality and adverse cardiovascular events. Vitamin D has important physiological functions beyond bone and calcium metabolism; thus, vitamin D receptors are expressed in skeletal and in cardiac muscle, indicating a potential functional role (18). Vitamin D deficiency leads to reduced calcium absorption and impaired muscle function $(19,20)$. Furthermore, the activated form of vitamin $\mathrm{D}, 1,25(\mathrm{OH})_{2} \mathrm{D}$, has been found to inhibit rennin-angiotensin activation $(21,22)$, reduce cardiac myocyte hypertrophy $(23)$ and reduce inflammation $(24,25)$.

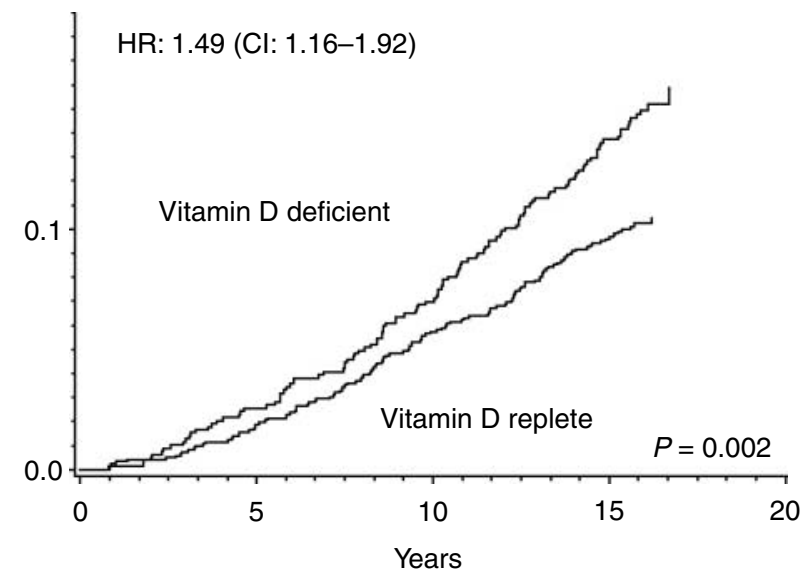

Figure 1 Risk of composite end point (death or hospitalisation due to heart failure, myocardial infarction or stroke) during 16 years of follow-up in 2013 postmenopausal women stratified according to vitamin $\mathrm{D}$ at baseline. 
Table 3 Occurrence of composite end point divided according to smoking habits (number (\%)) in vitamin D-sufficient and -deficient groups with hazard ratio (HR) of composite end point or mortality in vitamin D-deficient compared with vitamin D-replete participants.

\begin{tabular}{lllcll}
\hline & \multicolumn{3}{c}{ Events } \\
& $n$ (\% of subgroup) & & \\
\cline { 2 - 4 } $\begin{array}{l}\text { Composite } \\
\text { end point }\end{array}$ & $\begin{array}{c}\text { Vitamin D } \\
\text { deficient }\end{array}$ & $\begin{array}{c}\text { Vitamin } \mathrm{D} \\
\text { replete }\end{array}$ & $\begin{array}{c}\text { HR } \\
(95 \% \mathrm{Cl})\end{array}$ & $\boldsymbol{P}$ value \\
\hline Smokers & $74(20.1)$ & $72(15.8)$ & $1.32(0.97-1.83)$ & 0.091 \\
Non-smokers & $44(10.5)$ & $53(7.0)$ & $1.52(1.02-2.26)$ & 0.041 \\
\hline
\end{tabular}

The mean intake of vitamin D in DOPS women was $3.06 \mu \mathrm{g} /$ day, which is markedly lower than the recommendations by IOM of $600 \mathrm{IU}(15 \mu \mathrm{g})$ per day (recommending up to $4000 \mathrm{IU} /$ day as tolerable) (26). Even the vitamin D-replete women had a mean intake of vitamin $\mathrm{D}$ of $<5 \mu \mathrm{g} /$ day. We did not see any effect of the intake of vitamin D on outcome in our material - this is in line with previous findings (27). Furthermore, there was no effect of calcium intake on the primary end point nor on mortality or MI. These findings may contrast with earlier studies finding increased risk of MI (and possibly, though not significantly, mortality) with calcium supplements (28). However, in a recent study of 38772 older women, a reduced risk of mortality was reported with the use of calcium supplements (29). Also, a recent meta-analysis of randomised controlled trials supports the positive effects of vitamin D along with calcium, whereas vitamin $\mathrm{D}$ supplements alone were not found to reduce mortality (30). In another recent review and meta-analysis, the authors did not find significant reductions in mortality nor in cardiovascular risk associated with vitamin D supplementation (31). In most of the trials, the included subjects were not vitamin D deficient and doses were small ( $\leq 800 \mathrm{IU} /$ day). Thus, only in a limited selection did vitamin D-deficient subjects reach vitamin D repletion, and intervention was not long. Together, the evidence of effect of vitamin D on mortality or cardiovascular outcome still remains to be evaluated in large randomised controlled trials including vitamin D-deficient subjects and larger doses $(\geq 50 \mu \mathrm{g} /$ day $)$ of D3 for a prolonged period. Other meta-analyses describe reduced mortality with vitamin D supplements in randomised trials $(32,33)$.

The increase in cardiovascular morbidity with vitamin D deficiency seen in DOPS as well as in other populations, where up to a double 5-year risk of coronary heart disease with severe vitamin D deficiency (34) has been reported, seem biologically plausible. Vitamin D (25-OHD) is related to vascular endothelial function in healthy older adults (24). In 554 healthy subjects, $25(\mathrm{OH}) \mathrm{D}$ correlated with vascular function in subjects without traditional risk factors as well as in subjects with a number of risk factors, after adjusting for several confounders. Moreover, in subjects, that corrected vitamin D insufficiency an improvement in vascular function was seen (35). In a randomised trial, vitamin D supplements reduced arterial stiffness (36). Also in patients with type 2 diabetes and vitamin D deficiency, vitamin D treatment improved endothelial function (37). This may, partly, account for the association between vitamin D deficiency and hypertension $(1,38,39)$.

Vitamin D supplements to elderly women have shown to increase the oxidative muscle enzymes citrate synthase and 3-hydroxyacyl-CoA-dehydrogenase - this is a marker of improved muscle function (40). Also in children, the association between vitamin $\mathrm{D}$ and cardiac morbidity seems to be present - as seen in the NHANES study where vitamin D deficiency was associated with hypertension, low HDL-cholesterol levels and elevated PTH levels (39). Another possible cardio-protective effect of vitamin D may be via lipid regulation, as the association between vitamin D deficiency and a less favourable lipid profile has been reported earlier $(1,2,11,13,41)$. The positive correlation between $25(\mathrm{OH}) \mathrm{D}$ and HDL in postmenopausal women also seen in DOPS has previously been investigated and the subclass of large HDL was accounting for the difference (42). The positive correlation between $25(\mathrm{OH}) \mathrm{D}$ and HDL and inverse correlation of $25(\mathrm{OH}) \mathrm{D}$ with triglycerides are in line with the increased intima media thickness seen in subjects with carotid plaques from The Northern Manhattan Study (43). Finally, vitamin D may also act - indirectly - through PTH. Vitamin D deficiency leads to reduced calcium absorption with a tendency towards hypocalcaemia, which stimulates PTH secretion. Thus, decreasing vitamin D leads to increasing levels of PTH (44). Increased PTH for longer periods of time may indeed have harmful effects on the cardiovascular system $(7,45,46,47,48,49)$. The possible effects of vitamin D on the cardiovascular system have been discussed thoroughly in several overviews $(50,51,52,53)$.

Some studies have found the highest levels of 25-OHD to be associated with increasing mortality $(26,54,55)$, but we did not find this association in our material (data not shown). This may be due to residual confounding or differences of the populations, as the DOPS women were healthy at baseline, whereas other studies have included patients referred to testing for different reasons (54) or were population based (55).

Table 4 Predictors of the primary end point - results from multivariable analysis.

\begin{tabular}{llr}
\hline & \multicolumn{2}{c}{ Composite end point } \\
\cline { 2 - 3 } Full model & \multicolumn{1}{c}{$\mathrm{HR}(\mathrm{Cl})$} & $P$ value \\
\hline n/events & $1972(240)$ & \\
Vitamin D deficiency & $1.321(1.022-1.707)$ & 0.033 \\
Age (years) & $1.084(1.037-1.133)$ & $<0.001$ \\
Blood pressure (mmHg) & $1.014(1.008-1.020)$ & $<0.001$ \\
Hip-waist ratio & $0.248(0.091-0.672)$ & 0.006 \\
Family history of MI $(\mathrm{y} / \mathrm{n})$ & $1.664(1.069-2.527)$ & 0.017 \\
Smoking $(\mathrm{y} / \mathrm{n})$ & $2.321(1.775-3.007)$ & $<0.001$ \\
Degree of education & $0.819(0.675-0.993)$ & 0.043 \\
\hline
\end{tabular}




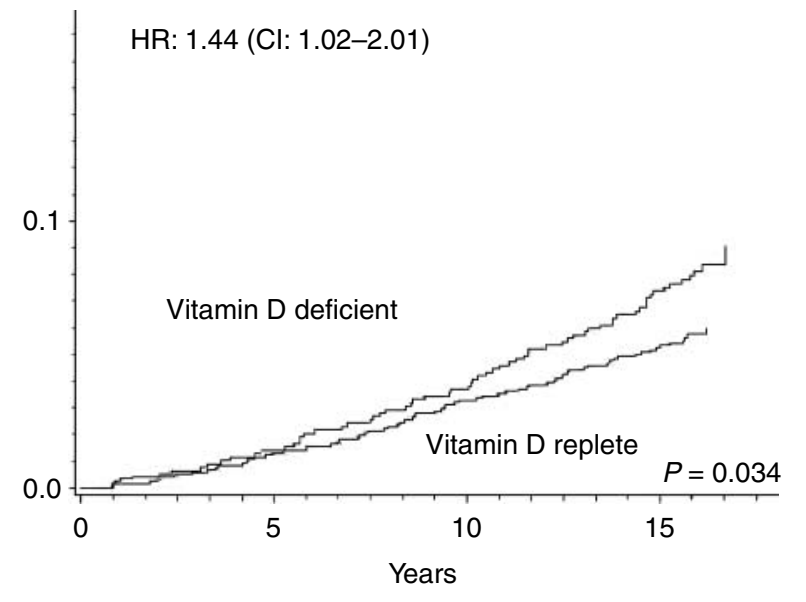

Figure 2 Risk of all-cause mortality during 16 years of follow-up in 2013 postmenopausal women stratified according to vitamin D at baseline.

A limitation is the observational nature of this study, which makes the causality uncertain. The population is - on the other hand - very well described at baseline, with several risk factors believed to be shared between vitamin $\mathrm{D}$ deficiency and cardiovascular disease, including family history, hip-waist ratio, blood pressure, smoking status, educational level, sedentary lifestyle and nutrition. Additionally, changes in intake of calcium and vitamin D supplements may have changed over time as these are available over-the-counter. This could potentially explain the lack of association between calcium intake and prognosis. However, it cannot explain the association between baseline 25(OH)D levels and prognosis. If important changes in intake occurred, this would tend to reduce the association between baseline values and long-term prognosis. Also, baseline vitamin D was only measured once at inclusion. Thus, patients may have seasonal fluctuations that would tend to diminish the association between $25(\mathrm{OH}) \mathrm{D}$ and outcome.

In conclusion, vitamin D deficiency is associated with lifestyle factors that have also been linked to adverse cardiovascular outcome. Even after adjusting for the variables that were important for the primary outcome, vitamin D deficiency was, in this population of healthy postmenopausal women, associated with increased risk of mortality, MI, HF or stroke.

\section{Declaration of interest}

P Eiken: Advisory board of Nycomed, Novartis; speaker's bureau with Amgen, Novartis, Eli Lilly, and GSK. J-E B Jensen: Advisory board and speaker's bureau of Nycomed, Eli Lilly, Novartis, MSD, Amgen.

\section{Funding}

The study was funded by University of Aarhus, Karen Elise Jensen's Foundation, Novo Nordic, Novartis and LEO Pharma. Role of the funding source: the sponsors of the study had no role in study design, data collection, data analysis, data interpretation or writing the report. Authors had full access to the data in the study and the final responsibility for the decision to submit for publication.

\section{Author contribution statement}

L Mosekilde contributed to the original design. This study was planned by J-E B Jensen, L L Schierbeck and L Køber. L Mosekilde, P Eiken, L Stilgren, C L Tofteng, L Rejnmark and J-E B Jensen implemented the study at different sites. L Rejnmark retrieved data from national registers. L Rejnmark, L Køber, C L Tofteng and L L Schierbeck organised the database. L L Schierbeck and L Køber had principal responsibility for the statistical analysis of the data. L L Schierbeck, L Køber, L Rejnmark and J-E B Jensen were active in the interpretation of the results. The report was drafted by L L Schierbeck and reviewed by all authors. All authors have approved the final report.

\section{References}

1 Vacek JL, Vanga SR, Good M, Lai SM, Lakkireddy D \& Howard PA. Vitamin D deficiency and supplementation and relation to cardiovascular health. American Journal of Cardiology 2012109 359-363. (doi:10.1016/j.amjcard.2011.09.020)

2 Dobnig H, Pilz S, Scharnagl H, Renner W, Seelhorst U, Wellnitz B, Kinkeldei J, Boehm BO, Weihrauch G \& Maerz W. Independent association of low serum 25-hydroxyvitamin D and 1,25-dihydroxyvitamin D levels with all-cause and cardiovascular mortality. Archives of Internal Medicine $2008 \mathbf{1 6 8}$ 1340-1349. (doi:10.1001/archinte.168.12.1340)

3 Holick MF. Sunlight and vitamin D for bone health and prevention of autoimmune diseases, cancers, and cardiovascular disease. American Journal of Clinical Nutrition 200480 1678S-1688S.

4 Holick MF. The vitamin D epidemic and its health consequences. Journal of Nutrition 2005135 2739S-2748S.

5 Lee JH, O'Keefe JH, Bell D, Hensrud DD \& Holick MF. Vitamin D deficiency: an important, common, and easily treatable cardiovascular risk factor? Journal of the American College of Cardiology 200852 1949-1956. (doi:10.1016/j.jacc.2008.08.050)

6 Pilz S, Marz W, Wellnitz B, Seelhorst U, Fahrleitner-Pammer A, Dimai HP, Boehm BO \& Dobnig H. Association of vitamin D deficiency with heart failure and sudden cardiac death in a large cross-sectional study of patients referred for coronary angiography. Journal of Clinical Endocrinology and Metabolism 200893 3927-3935. (doi:10.1210/jc.2008-0784)

7 Schierbeck LL, Jensen TS, Bang U, Jensen G, Kober L \& Jensen JE. Parathyroid hormone and vitamin D - markers for cardiovascular and all cause mortality in heart failure. European Journal of Heart Failure 201113 626-632. (doi:10.1093/eurjhf/hfr016)

8 Zittermann A \& Koerfer R. Vitamin D in the prevention and treatment of coronary heart disease. Current Opinion in Clinical Nutrition and Metabolic Care 200811 752-757. (doi:10.1097/ MCO.0b013e328312c33f)

9 Shapses SA \& Manson JE. Vitamin D and prevention of cardiovascular disease and diabetes: why the evidence falls short. Journal of the American Medical Association 2011305 2565-2566. (doi:10.1001/jama.2011.881)

10 Mullie P \& Autier P. Relation of vitamin D deficiency to cardiovascular disease. American Journal of Cardiology 2011107 956-957. (doi:10.1016/j.amjcard.2010.10.079)

11 Chacko SA, Song Y, Manson JE, Van Horn L, Eaton C, Martin LW, McTiernan A, Curb JD, Wylie-Rosett J, Phillips LS, Plodkowski RA \& Liu S. Serum 25-hydroxyvitamin D concentrations in relation to cardiometabolic risk factors and metabolic syndrome in postmenopausal women. American Journal of Clinical Nutrition 201194 209-217. (doi:10.3945/ajcn.110.010272)

12 Holick MF. Vitamin D deficiency. New England Journal of Medicine 2007357 266-281. (doi:10.1056/NEJMra070553) 
13 Mosekilde L. Vitamin D and the elderly. Clinical Endocrinology 2005 62 265-281. (doi:10.1111/j.1365-2265.2005.02226.x)

14 Holick MF. The photobiology of vitamin D and its consequences for humans. Annals of the New York Academy of Sciences $1985 \mathbf{4 5 3}$ 1-13. (doi:10.1111/j.1749-6632.1985.tb11793.x)

15 Lund B \& Sorensen OH. Measurement of 25-hydroxyvitamin D in serum and its relation to sunshine, age and vitamin D intake in the Danish population. Scandinavian Journal of Clinical and Laboratory Investigation 197939 23-30. (doi:10.3109/ 00365517909104935)

16 Mosekilde L, Hermann AP, Beck NH, Charles P, Nielsen SP \& Sorensen $\mathrm{OH}$. The Danish Osteoporosis Prevention Study (DOPS): project design and inclusion of normal perimenopausal women. Maturitas 200031 207-219. (doi:10.1016/S03785122(99)00006-7)

17 Andersen TF, Madsen M, Jorgensen J, Mellemkjoer L \& Olsen JH. The Danish National Hospital Register. A valuable source of data for modern health sciences. Danish Medical Bulletin 199946 263-268.

18 O'Connell TD \& Simpson RU. Immunochemical identification of the 1,25-dihydroxyvitamin D3 receptor protein in human heart. Cell Biology International 199620 621-624. (doi:10.1006/cbir. 1996.0081)

19 Visser M, Deeg DJ \& Lips P. Low vitamin D and high parathyroid hormone levels as determinants of loss of muscle strength and muscle mass (sarcopenia): the Longitudinal Aging Study Amsterdam. Journal of Clinical Endocrinology and Metabolism 2003 88 5766-5772. (doi:10.1210/jc.2003-030604)

20 Montero-Odasso M \& Duque G. Vitamin D in the aging musculoskeletal system: an authentic strength preserving hormone. Molecular Aspects of Medicine 200526 203-219. (doi:10.1016/ j.mam.2005.01.005)

$21 \mathrm{Li} \mathrm{YC,} \mathrm{Kong} \mathrm{J,} \mathrm{Wei} \mathrm{M,} \mathrm{Chen} \mathrm{ZF,} \mathrm{Liu} \mathrm{SQ} \mathrm{\&} \mathrm{Cao} \mathrm{LP.} \mathrm{1,25-}$ Dihydroxyvitamin $\mathrm{D}(3)$ is a negative endocrine regulator of the renin-angiotensin system. Journal of Clinical Investigation 2002 $110229-238$.

$22 \mathrm{Li} \mathrm{YC.} \mathrm{Vitamin} \mathrm{D} \mathrm{regulation} \mathrm{of} \mathrm{the} \mathrm{renin-angiotensin} \mathrm{system.}$ Journal of Cellular Biochemistry 200388 327-331. (doi:10.1002/ jcb.10343)

23 Chen S, Law CS, Grigsby CL, Olsen K, Hong TT, Zhang Y, Yeghiazarians Y \& Gardner DG. Cardiomyocyte-specific deletion of the vitamin D receptor gene results in cardiac hypertrophy. Circulation 2011 124 1838-1847. (doi:10.1161/CIRCULATIONAHA.111.032680)

24 Jablonski KL, Chonchol M, Pierce GL, Walker AE \& Seals DR. 25-Hydroxyvitamin D deficiency is associated with inflammationlinked vascular endothelial dysfunction in middle-aged and older adults. Hypertension 201157 63-69. (doi:10.1161/HYPERTENSIONAHA.110.160929)

25 Schleithoff SS, Zittermann A, Tenderich G, Berthold HK, Stehle P \& Koerfer R. Vitamin D supplementation improves cytokine profiles in patients with congestive heart failure: a double-blind, randomized, placebo-controlled trial. American Journal of Clinical Nutrition 200683 754-759.

26 Institute of Medicine. Dietary reference intakes for vitamin D and Calcium. Washington, DC: The National Academies Press, 2010.

27 Sun Q, Shi L, Rimm EB, Giovannucci EL, Hu FB, Manson JE \& Rexrode KM. Vitamin D intake and risk of cardiovascular disease in US men and women. American Journal of Clinical Nutrition 2011 94 534-542. (doi:10.3945/ajcn.110.008763)

28 Bolland MJ, Avenell A, Baron JA, Grey A, MacLennan GS, Gamble GD \& Reid IR. Effect of calcium supplements on risk of myocardial infarction and cardiovascular events: meta-analysis. BMJ 2010341 c3691. (doi:10.1136/bmj.c3691)

29 Mursu J, Robien K, Harnack LJ, Park K \& Jacobs DR Jr. Dietary supplements and mortality rate in older women: the Iowa Women's Health Study. Archives of Internal Medicine 2011171 1625-1633. (doi:10.1001/archinternmed.2011.445)

30 Rejnmark L, Avenell A, Masud T, Anderson F, Meyer HE, Sanders KM, Salovaara K, Cooper C, Smith HE, Jacobs ET, Torgerson D, Jackson RD, Manson JE, Brixen K, Mosekilde L,
Robbins JA, Francis RM \& Abrahamsen B. Vitamin D with calcium reduces mortality: patient level pooled analysis of 70,528 patients from eight major vitamin D trials. Journal of Clinical Endocrinology and Metabolism $2012 \quad 97$ 2670-2681. (doi:10.1210/jc.2011-3328)

31 Elamin MB, Abu Elnour NO, Elamin KB, Fatourechi MM, Alkatib AA, Almandoz JP, Liu H, Lane MA, Mullan RJ, Hazem A, Erwin PJ, Hensrud DD, Murad MH \& Montori VM. Vitamin D and cardiovascular outcomes: a systematic review and metaanalysis. Journal of Clinical Endocrinology and Metabolism 201196 1931-1942. (doi:10.1210/jc.2011-0398)

32 Autier P \& Gandini S. Vitamin D supplementation and total mortality: a meta-analysis of randomized controlled trials. Archives of Internal Medicine $2007 \quad 167$ 1730-1737. (doi:10.1001/ archinte.167.16.1730)

33 Bjelakovic G, Gluud LL, Nikolova D, Whitfield K, Wetterslev J, Simonetti RG, Bjelakovic M \& Gluud C. Vitamin D supplementation for prevention of mortality in adults. Cochrane Database of Systematic Reviews, 2011 CD007470.

34 Wang TJ, Pencina MJ, Booth SL, Jacques PF, Ingelsson E, Lanier K, Benjamin EJ, D'Agostino RB, Wolf M \& Vasan RS. Vitamin D deficiency and risk of cardiovascular disease. Circulation 2008117 503-511. (doi:10.1161/CIRCULATIONAHA.107.706127)

35 Al Mheid I, Patel R, Murrow J, Morris A, Rahman A, Fike L, Kavtaradze N, Uphoff I, Hooper C, Tangpricha V, Alexander RW, Brigham K \& Quyyumi AA. Vitamin D status is associated with arterial stiffness and vascular dysfunction in healthy humans. Journal of the American College of Cardiology 201158 186-192. (doi:10.1016/j.jacc.2011.02.051)

36 Dong Y, Stallmann-Jorgensen IS, Pollock NK, Harris RA, Keeton D, Huang Y, Li K, Bassali R, Guo DH, Thomas J, Pierce GL, White J, Holick MF \& Zhu H. A 16-week randomized clinical trial of 2000 international units daily vitamin D3 supplementation in black youth: 25-hydroxyvitamin D, adiposity, and arterial stiffness. Journal of Clinical Endocrinology and Metabolism 201095 4584-4591. (doi:10.1210/jc.2010-0606)

37 Sugden JA, Davies JI, Witham MD, Morris AD \& Struthers AD. Vitamin D improves endothelial function in patients with Type 2 diabetes mellitus and low vitamin D levels. Diabetic Medicine 2008 25 320-325. (doi:10.1111/j.1464-5491.2007.02360.x)

38 Anderson JL, May HT, Horne BD, Bair TL, Hall NL, Carlquist JF, Lappé DL \& Muhlestein JB. Relation of vitamin D deficiency to cardiovascular risk factors, disease status, and incident events in a general healthcare population. American Journal of Cardiology 2010106 963-968. (doi:10.1016/j.amjcard.2010.05.027)

39 Kumar J, Muntner P, Kaskel FJ, Hailpern SM \& Melamed ML. Prevalence and Associations of 25-Hydroxyvitamin D Deficiency in US Children: NHANES 2001-2004. Pediatrics 2009 124 e362-e370. (doi:10.1542/peds.2009-0051)

40 Hansen B. Vitamin D and elderly women. PhD Thesis 2003.

41 Giovannucci E, Liu Y, Hollis BW \& Rimm EB. 25-Hydroxyvitamin $\mathrm{D}$ and risk of myocardial infarction in men: a prospective study. Archives of Internal Medicine 2008168 1174-1180. (doi:10.1001/ archinte.168.11.1174)

42 Kazlauskaite R, Powell LH, Mandapakala C, Cursio JF, Avery EF \& Calvin J. Vitamin D is associated with atheroprotective high-density lipoprotein profile in postmenopausal women. Journal of Clinical Lipidology 2010 4 113-119. (doi:10.1016/ j.jacl.2010.01.006)

43 Carrelli AL, Walker MD, Lowe H, McMahon DJ, Rundek T, Sacco RL \& Silverberg SJ. Vitamin D deficiency is associated with subclinical carotid atherosclerosis: the Northern Manhattan study. Stroke $2011 \mathbf{4 2}$ 2240-2245. (doi:10.1161/STROKEAHA. 110.608539)

44 Pepe J, Romagnoli E, Nofroni I, Pacitti MT, De Geronimo S, Letizia C, Tonnarini G, Scarpiello A, D’Erasmo E \& Minisola S. Vitamin D status as the major factor determining the circulating levels of parathyroid hormone: a study in normal subjects. Osteoporosis International 200516 805-812. (doi:10.1007/ s00198-004-1757-4) 
45 Andersson P, Rydberg E \& Willenheimer R. Primary hyperparathyroidism and heart disease - a review. European Heart Journal 200425 1776-1787. (doi:10.1016/j.ehj.2004.07.010)

46 Costa-Hong V, Jorgetti V, Gowdak LH, Moyses RM, Krieger EM \& De Lima JJ. Parathyroidectomy reduces cardiovascular events and mortality in renal hyperparathyroidism. Surgery $2007 \mathbf{1 4 2}$ 699-703. (doi:10.1016/j.surg.2007.06.015)

47 Hagstrom E, Hellman P, Larsson TE, Ingelsson E, Berglund L, Sundstrom J, Melhus H, Held C, Lind L, Michaelsson K \& Arnlov J. Plasma parathyroid hormone and the risk of cardiovascular mortality in the community. Circulation $20091192765-2771$. (doi:10.1161/CIRCULATIONAHA.108.808733)

48 Jorde R, Svartberg J \& Sundsfjord J. Serum parathyroid hormone as a predictor of increase in systolic blood pressure in men. Journal of Hypertension 200523 1639-1644. (doi:10.1097/01. hjh.0000179764.40701.36)

49 Kamycheva E, Sundsfjord J \& Jorde R. Serum parathyroid hormone levels predict coronary heart disease: the Tromso Study [Article]. European Journal of Cardiovascular Prevention and Rehabilitation 200411 69-74. (doi:10.1097/01.hjr.00001147 $06.27531 .01)$

50 Cozzolino M, Ketteler M \& Zehnder D. The vitamin D system: a crosstalk between the heart and kidney. European Journal of Heart Failure 201012 1031-1041. (doi:10.1093/eurjhf/hfq112)
51 Nemerovski CW, Dorsch MP, Simpson RU, Bone HG, Aaronson KD \& Bleske BE. Vitamin D and cardiovascular disease. Pharmacotherapy 200929 691-708. (doi:10.1592/phco.29.6.691)

52 Pilz S, Tomaschitz A, Drechsler C, Dekker JM \& Marz W. Vitamin D deficiency and myocardial diseases. Molecular Nutrition $\mathcal{E}$ Food Research 201054 1103-1113. (doi:10.1002/mnfr.200900474)

53 Rosen CJ, Adams JS, Bikle DD, Black DM, Demay MB, Manson JE, Murad MH \& Kovacs CS. The nonskeletal effects of vitamin D: an endocrine society scientific statement. Endocrine Reviews 2012 33 456-492. (doi:10.1210/er.2012-1000)

54 Durup D, Jorgensen HL, Christensen J, Schwarz P, Heegaard AM \& Lind B. A reverse J-shaped association of all-cause mortality with serum 25-hydroxyvitamin D in general practice, the CopD Study. Journal of Clinical Endocrinology and Metabolism 201297 2644-2652. (doi:10.1210/jc.2012-1176)

55 Melamed ML, Michos ED, Post W \& Astor B. 25-Hydroxyvitamin D levels and the risk of mortality in the general population. Archives of Internal Medicine $2008 \mathbf{1 6 8}$ 1629-1637. (doi:10.1001/ archinte.168.15.1629)

Received 30 March 2012

Revised version received 19 June 2012

Accepted 8 August 2012 